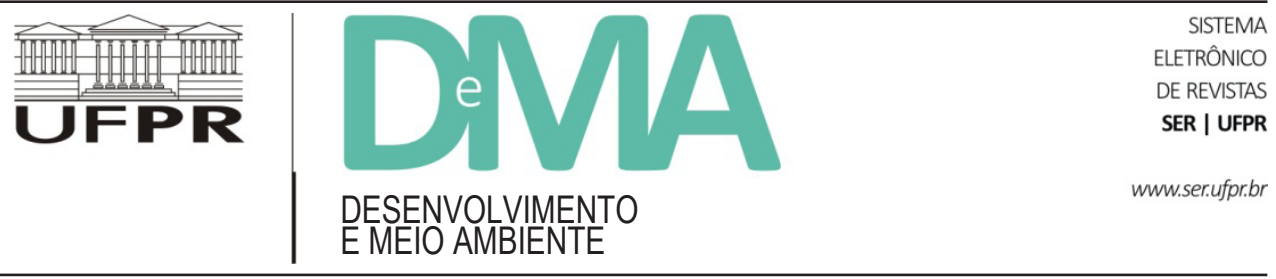

\title{
A ecomotricidade na apreensão da natureza: inter-ação como experiência lúdica e ecológica
}

\author{
Ecomotricity in the apprehension of nature: \\ inter-action as a ludic and ecological experience
}

\author{
Cae RODRIGUES ${ }^{1 *}$ \\ ${ }^{1}$ Universidade Federal de Sergipe (UFS), São Cristóvão, SE, Brasil. \\ *E-mail de contato: rodrigues.cae@gmail.com
}

Artigo recebido em 27 de novembro de 2018, versão final aceita em 20 de maio de 2019.

RESUMO: Desdobrando-se sobre a compreensão de que as concepções de ambiente são construídas a partir das experiências de movimento (motricidade), o presente artigo foca na ecomotricidade, compreendida como a inter-ação lúdica e ecológica com a natureza. Dessa forma, o objetivo do artigo é conceituar e contextualizar horizontes da natureza apreendidos a partir de experiências lúdicas (significadas pela alegria/prazer) na natureza, especialmente na medida em que se evidenciam processos de incorporação (naturalização) de preceitos ecosomaestéticos-ambientalmente éticos-ecopolíticos no habitus de movimento. As inferências sobre o tema são contextualizadas a partir de dados coletados em um projeto de pesquisa sobre a ecomotricidade no estado de Sergipe (2014-2017), no qual diferentes métodos (entrevistas; observações diretas em etnografias em movimento; narrativas diversificadas; análise de perfis sociais; análises linguísticas) foram utilizados para compreender as intencionalidades de inter-ação com o meio de indivíduos com vivências lúdicas regulares na natureza, assim como as relações e visões de mundo são (re)construídas a partir dessas vivências. A partir dessa perspectiva analítica, a discussão foca a ecomotricidade na apreensão da natureza, perspectiva específica no âmbito mais amplo das discussões sobre relações ser humano (sociedade)-natureza (mundo), pela qual vislumbra-se considerações do movimento imanente de humanos-e-não-humanos-sendo-com-a-natureza, em oposição a uma visão antropocêntrica de "conexão à natureza". Entre os principais resultados da pesquisa apresentada, discute-se como os elementos "tempo" e "imersão" se destacam na macroanálise sobre a apreensão de horizontes da natureza a partir da ecomotricidade, sendo também apresentada uma síntese crítica como princípios possivelmente transferíveis (não generalizáveis) da ecomotricidade, vislumbrando contribuir para o debate sobre possibilidades e limitações da incorporação de preceitos ecológicos no habitus de movimento de indivíduos a partir de experiências lúdicas na natureza.

Palavras-chave: meio ambiente; fenomenologia do corpo; técnica; lúdico; estética. 
ABSTRACT: Having as a starting point the idea that conceptualizations of the environment are built from movement experiences (motricity), this article focuses on ecomotricity, which is understood as the ludic and ecological inter-action with nature. Thus, the article aims to conceptualize and contextualize horizons of nature apprehended in ludic experiences (signified by joy/pleasure) in nature, especially as it allocates/awards the incorporation (naturalization) of ecosomaesthetic-environmentally ethical-ecopolitical precepts into the habitus of movement. Inferences about the subject are contextualized using data from a research project on ecomotricity in the state of Sergipe - Brazil (2014-2017), in which different methods (interviews; direct observations in moving ethnographies; diversified narratives; social profile analysis; linguistic analysis) were used to understand the intentionalities in inter-acting with the environment of individuals with regular ludic experiences in nature, as well as how relationships and worldviews are (re)constituted in these experiences. From this analytical perspective, the discussion focuses on ecomotricity in the apprehension of nature, a specific perspective in the broader scope of the discussions about human (society)-nature (world) relations in which considerations are possible on the immanent movement of humans-and-other-than-humans-being-with-nature, an opposition to an anthropocentric view of a "connection to nature". Among the main results of the presented research, I discuss how "time" and "immersion" stand out in the macro-analysis on apprehensions of nature in ecomotricity; additionally, critical synthesis is also presented as possibly transferable (not generalizable) principals of ecomotricity, aiming to contribute to the debate about possibilities and limitations of the incorporation of ecological precepts in the habitus of movement of individuals through ludic experiences in nature.

Keywords: environment; phenomenology of the body; technique; play; aesthetics.

\section{Introdução}

O presente artigo se desdobra sobre a compreensão de que as concepções de ambiente são construídas a partir das experiências de movimento de seres (humanos) sendo-ao-mundo (motricidade). Mais especificamente, considerando o objetivo de conceituação e contextualização dos horizontes da natureza incorporados ao habitus de movimento de indivíduos a partir de suas experiências na natureza, o presente artigo foca na ecomotricidade, compreendida como a inter-ação lúdica (quando o prazer ou a alegria dão significado à experiência vivida) e ecológica (ecosomaestética-ambientalmente ética-ecopolítica) com/na natureza.

Segundo Bourdieu (1989), o conceito de habitus diz respeito às disposições, percepções e ações naturalizadas pelo indivíduo em sua trajetória de vida. Ao ser convertido em diferentes formas de capital, o habitus determina as dinâmicas (hierarquias) de posicionamento do indivíduo nos campos ou espaços sociais. Apresentando o campo como estrutura relacional e sistêmica, Bourdieu pretende superar a antinomia convencionalmente existente nas ciências humanas entre o objetivismo (preponderância das estruturas sociais sobre as ações do sujeito) e o subjetivismo (primazia da ação do sujeito em relação às determinações sociais). Nesse sentido, compreende-se por "habitus de movimento" o conjunto de ações de movimento que são naturalizados pelo indivíduo - para os propósitos deste artigo, especificamente, em experiências na natureza. A premissa é que esse habitus de movimento é convertido em uma forma específica de capital "ecológico", passando a ter influência direta sobre o posicionamento do indivíduo em diferentes espaços sociais (de modo geral, de acordo com o grau de legitimação do capital ecológico nesses espaços) ${ }^{1}$.

\footnotetext{
1 Essa discussão é bem desenvolvida por Carvalho (2010) a partir da conceituação do "habitus ecológico".
} 
Sobre a conceituação da perspectiva ecológica a partir da tríade "ecosomaestética-ética ambiental-ecopolítica", concebe-se por ecosomaestética a constituição (ou resultado) de uma experiência particular na relação com o ambiente (Payne, 2013): o prefixo "eco" significa uma disposição não antropocêntrica, enquanto "Soma" localiza essa disposição na senciência do ser humano e actância de corpos não humanos na natureza; desse modo, somaestética refere-se à geração corporal (estética ${ }^{2}$ ) de significados (Payne et al., 2018), sendo a ecosomaestética a geração corporal de significados a partir de uma disposição ecocêntrica (não-antropocêntrica, ou biocêntrica). $\mathrm{O}$ uso do hífen (ou do til, usado no mesmo sentido em Payne, 2015) tem como objetivo salientar o caráter dinâmico e relacional entre os conceitos apresentados (ecosomaestética-ética ambiental-ecopolítica). Nesse sentido, reconhece-se a fragilidade de uma conceituação desses termos sem a devida consideração sobre as dinâmicas pelas quais continuamente se constituem, exercendo poder e força um sobre o outro, não sendo possível uma caracterização linear ou unilateral.

Mirando esse horizonte ecológico, conceitualmente, a ecomotricidade advoga por uma mudança de paradigma alinhada com alguns pressupostos da "fenomenologia da percepção" (Merleau-Ponty, 1996); da "fenomenologia do corpo" (Ingold, 2000; 2011); da "ecofenomenologia" (Brown \& Toadvine, 2003); e do que é referenciado na teoria contemporânea como uma "virada corporal" (Sheets-Johnstone, 2009) ou "intercorporeidade" (Gallagher, 2016, com interpretações particulares para o campo ambiental em Payne, 1997; 2013). Em seu conjunto, tais correntes ou teorias consolidam um pressuposto fundamental para a conceituação da "motricidade" - o corpo (ser) como unidade sensorial indivisível, sendo o movimento desse corpo-ao-mundo a essência primordial da criação de significados. A partir desse pressuposto, o conceito de motricidade concebe um corpo de ação contínua, um corpo vivo de/em movimento intencional e transcendente ao mundo; a ecomotricidade vislumbra esse corpo vivo, mais especificamente, em ação interativa na/ com a natureza, na medida em que essa interação é significada como lúdica e ecológica.

Ampliando o escopo de ontologias, epistemologias e metodologias nas quais o movimento humano é concebido de forma mecânica, instrumental, funcional e performativa, o conceito de ecomotricidade abrange maneiras de se mover na/ com a natureza que antecipam uma compreensão somática/somaestética das experiências lúdicas do corpo em movimento em um tempo kairos (relatividade do tempo ao corpo particular, em oposição ao tempo resolvido e inabalável do relógio pronunciado no chronos - Rodrigues \& Stevaux, 2010) e em um espaço chora (situado entre o sensível e o inteligível, pronuncia a ambiguidade onde ocorre o espaço, enquanto topos sugere mera localização ou características objetivas de um lugar - Walter, 1988). No campo conceitual, o movimento na dimensão kairos-chora se associa ao conceito de affordance (Gibson, 1979), expressando o encontro das disponibilidades (e consequentes possibilidades) estruturais do ambiente e a capacidade estrutural do agente em perceber o que é acessível às suas ações.

\footnotetext{
2 O conceito de "estética" aqui empregado resgata o sentido filosófico de "aiesthesis", compreendendo a experiência sensível e a formação de sensibilidades que movem nossa ação no mundo. Para uma leitura mais aprofundada sobre essa conceituação de estética, incluindo como tal é contextualizada no âmbito da pesquisa em educação ambiental, sugere-se a leitura de Payne et al. (2018).
} 
Com base nas características apresentadas, a ecomotricidade (em suas dimensões ontológicas, epistemológicas e metodológicas) instiga questionamentos sobre: (a) maneiras de se mover em diferentes ambientes, assim como as formas de inter-ação e as relações corpo-ambiente construídas a partir desses movimentos; (b) tendências históricas do movimento em categorias (socialmente legitimadas) de fisicalidade/habilidade, idade, gênero, etnia, classe - por exemplo, em experiências esportivas e recreativas na natureza; (c) conjuntos idealizados ou romantizados de formas e estilos (desejados; imaginados; fantasiados) de movimento construídos nas relações corpo-ambiente; (d) o foco antropocêntrico da motricidade como qualidade exclusivamente humana.

As inferências sobre tais questionamentos são contextualizadas neste artigo a partir de publicações anteriores sobre os desenvolvimentos conceituais, pedagógicos e metodológicos da ecomotricidade (Rodrigues \& Gonçalves Junior, 2009; Rodrigues, 2018), assim como dados coletados no projeto de pesquisa "A ecomotricidade no estado de Sergipe", vinculado ao Departamento de Educação Física da Universidade Federal de Sergipe (UFS) e desenvolvido entre os anos de 2014 e $2017^{3}$. Durante os três anos de atividades, o projeto investigou exemplos locais (município de Aracaju-SE) de relações corpo-natureza objetivando a identificação de "categorias de movimento" que substanciassem a análise sobre: (a) como contextos de ecomotricidade influenciam relações corpo-natureza; e (b) como relações ser humano-natureza em contextos de ecomotricidade influenciam a (re)constituição de visões de mundo. O projeto foi desenvolvido a partir de três fases interconectadas: (a) análise textual qualitativa de artigos publicados em periódicos brasileiros que abordam relações corpo-natureza; (b) pesquisa de campo a partir de métodos etnográficos/ecofenomenológicos observando exemplos locais de relações corpo-natureza; e (c) diálogo aberto entre pesquisadores e esfera pública sobre dados e resultados da pesquisa a partir de tecnologias virtuais (interações em plataforma digital criada especificamente para esse propósito).

Neste artigo, serão apresentados alguns dados da segunda fase do projeto (pesquisa de campo), evidenciando, a partir da máxima fenomenológica de "ir à coisa mesma" (Rodrigues et al., 2010), particularidades representativas de interações corpo-meio ambiente observadas pela com-vivência ${ }^{4}$ com indivíduos que possuem experiências regulares de interação na natureza, sendo a regularidade definida pela frequência média de pelo menos uma vez por semana nos últimos dois anos (ou mais). A

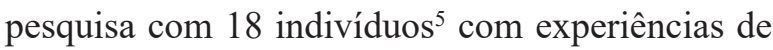
surfe, mountain bike, SUP, caminhadas, corridas de montanha e de rua, patinação e skate foi conduzida a

\footnotetext{
${ }^{3}$ Durante os três anos de desenvolvimento, o projeto (identificado no SIGAA-UFS pelos códigos PVA2259-2014, PVA3354-2015 e PVA44212016) teve a participação de 12 pesquisadores de 9 instituições diferentes, 9 alunos de graduação e 1 aluno do mestrado, contando com os seguintes financiamentos: HERMES (compra de material); CNPq e CAPES-UFS (bolsas de Iniciação Científica).

${ }^{4}$ O termo "com-vivência" é apresentado dessa maneira objetivando a ênfase no caráter humano implícito na expressão, ou seja, o "viver com", que significa considerar a complexa teia de relações de seres humanos sendo-uns-com-os-outros. O caráter dinâmico da expressão também deve ser salientado, apresentado especialmente pelo uso do hífen (usual principalmente na fenomenologia), pois homens e mulheres não são no mundo como objetos estáticos; estão sendo ao mundo num movimento constante e transformador (Rodrigues, 2015).

${ }^{5}$ Os participantes da pesquisa foram escolhidos por indicação (por conhecimento prévio) dos próprios pesquisadores do projeto de pesquisa (docentes e discentes), sendo afirmada a participação no projeto a partir da confirmação da regularidade de vivências na natureza pelo próprio participante (seguindo os critérios de regularidade adotados pela pesquisa) e da assinatura do Termo de Consentimento Livre e Esclarecido aprovado pelo Certificado de Apresentação para Apreciação Ética (número 47369615.5.0000.5546).
} 
partir de um framework etnográfico/ecofenomenológico desenvolvido a partir de oito etapas, tendo como foco: (a) constituições/representações estéticas da experiência; (b) associações e dissociações entre as experiências e o cotidiano dos colaboradores; (c) perfis de personalidade dos indivíduos envolvidos com as várias experiências. A partir dessa perspectiva analítica, a discussão desenvolvida no artigo tem como foco a ecomotricidade na apreensão da natureza, perspectiva específica no âmbito mais amplo das relações ser humano/sociedade-natureza pela qual se vislumbra considerações do movimento imanente de humanos-e-não-humanos-sendo-com-a-natureza, em oposição a uma visão antropocêntrica de "conexão à natureza".

Objetivando uma melhor contextualização conceitual do problema abordado, a primeira seção do manuscrito é dedicada à apresentação das perspectivas ecológicas da motricidade. Posteriormente, são delineados os procedimentos metodológicos para a coleta e a análise dos dados que dão sustentação empírica à discussão proposta no artigo, seguido da apresentação e discussão dos principais resultados da pesquisa empírica. Finalmente, apresento uma síntese crítica como princípios possivelmente transferíveis (não generalizáveis) da ecomotricidade, vislumbrando contribuir para o debate sobre possibilidades e limitações da incorporação de preceitos ecológicos no habitus de movimento de indivíduos a partir de experiências lúdicas na natureza.

\section{2. "Ecos" da motricidade}

Um duplo sentido é instigado pelo título desta seção: possibilidades que se abrem (ecoam) a partir da conceituação do mundo significado pela perspectiva da motricidade; e possíveis horizontes ecológicos da motricidade. Desvelar os contextos práxicos de ambos esses sentidos é essencial para a compreensão das potencialidades pedagógicas e metodológicas da ecomotricidade.

A discussão sobre as possibilidades que se abrem a partir do mundo significado pela perspectiva da motricidade se torna pertinente na medida em que se cria a oposição entre essa perspectiva e outras conceituações de mundo, especialmente, as associadas a correntes filosóficas materialistas e positivistas, que ocupam posições de dominância em praticamente todos os espaços sociais. Considerando tal oposição a partir de perspectivas centradas no movimento, destacam-se os contrastes entre um "mundo em movimento" e um "mundo de movimento" (Rodrigues, 2018). A perspectiva de um "mundo em movimento" pressupõe um mundo materialmente constituído, sendo que toda matéria está em constante movimento; nesse contexto, um sistema ao mesmo tempo complexo e caótico determina as possibilidades de interação dos seres vivos e objetos que se encontram no mundo, sendo a racionalidade ponto essencial para a determinação das interações objetivas. Já a perspectiva de um "mundo de movimento" pressupõe que os próprios mundos são constituídos em e pelo movimento, ou seja, só há um mundo (tempo-espaço) porque eu tenho um corpo que se move - corpo que não é uma região física, mas uma região ontológica na qual a existência é constituída objetivamente (Husserl, 1988).

Conceitualmente, a perspectiva de um mundo de movimento (alinhado a uma visão fenomenológica do ser-ao-mundo) tem tido importante impacto nos estudos ambientais, especialmente, nos últimos 20 anos, fazendo parte desse movimento as já citadas correntes/teorias da ecofenomenologia, fenomenologia do corpo, virada corporal e intercorporeidade. Tais exemplos são representativos entre movimentos caracterizados como holísticos ou ontológicos (no sentido de um retorno ao corpo 
ou à essência do "ser"), diferenciando-se como "alternativos" ao "tradicional" (cartesiano-materialista-positivista) pela aclamação do primado não da razão, mas da percepção - determinada por uma relação corpo-mundo integral (dialógica e não-fragmentária) - como principal intermediação do corpo no/com o mundo. Essa perspectiva de um "corpo encarnado" (Merleau-Ponty, 1996), pela qual o corpo não é o "resultado simples das associações estabelecidas ao longo da experiência, mas uma consciência holística/ecológica da minha postura no mundo intersensorial" (p. 143), é essencial para a concepção da motricidade como "intencionalidade original" - unidade integrada de uma consciência imbuída de intencionalidade e de um corpo dotado de movimento, gerando significado existencial (Sérgio, 2003).

Retomando o "eco" da motricidade (em ambos os sentidos), a essência relacional e intercorpórea do ser-ao-mundo pressuposta pelo conceito de motricidade tem profundas implicações ecológicas, principalmente a partir de questionamentos a formas e estilos (socialmente legitimados) de movimento na natureza, considerando categorias como fisicalidade/habilidade, idade, gênero, etnia, classe, assim como conjuntos idealizados/romantizados de movimento construídos nas relações corpo-ambiente. No entanto, outra perspectiva que emerge da concepção ecológica da motricidade - a saber, as motricidades de corpos/seres/ambientes não-humanos - contesta uma noção fundamental do conceito original de motricidade: tendo como pilares conceituais os princípios fenomenológicos de intencionalidade e transcendência, a motricidade é originalmente concebida como uma qualidade exclusivamente humana.

A desconstrução dessa concepção originária objetivando a formulação de um conceito mais abrangente de motricidade implicaria, necessa- riamente, um desafio aos escopos predefinidos de transcendência e intencionalidade: estendendo-se além da ideia antropocêntrica de uma "consciência" transcendental atribuída exclusivamente à relação ser humano-objeto, o conceito de transcendência teria de ser compreendido como o tecido sensorial da sobrevivência sentida por todos os seres vivos, um senso compartilhado que impele todos os seres ao movimento e à inter-ação; quanto à intencionalidade, compreendida como "comportamento corpóreo-mundano e existencial, no qual se constitui e reconstitui o mundo significado" (Fiori, 1986, p. 4), é necessário o reconhecimento de que a significação do mundo não é uma qualidade exclusivamente humana - um pássaro escolhendo um parceiro sexual, ou alimentando seus filhotes no ninho, ou uma árvore brotando uma nova folha procurando pelo sol, ou decidindo a direção de um novo galho, são exemplos de mundos/ambientes significados, inerentemente constituídos por meio de inter-ações intercorpórea-mundanas e existenciais que, invariavelmente, são mutuamente presenciadas, co-constitutivas e recíprocas.

Outra característica distinta da ecomotricidade é a atenção ao caráter lúdico da relação corpo-meio ambiente, compreendendo o lúdico como a essência do prazer ou da alegria/felicidade que dá significado a uma experiência vivida, sendo os limites contextuais (temporais e espaciais) da ludicidade definidos objetivamente a partir das interações particulares corpo-mundo. Dessa forma, uma interação é lúdica quando o prazer ou a alegria/felicidade dão significado à experiência vivida (sempre circunstancial - a interação é lúdica para aquele corpo, naquele contexto temporal e espacial específico). Retomando a discussão sobre a descentralização do humano na perspectiva da ecomotricidade, não é difícil imaginarmos como lúdicas as experiências de um cachorro ou gato se divertindo com seus brinquedos 
ou interagindo com seus comparsas humanos; ou mesmo de um filhote selvagem brincando com seus irmãos ou pais. Mas será que podemos ultrapassar essas barreiras nas quais conseguimos imaginar com maior facilidade uma potencialidade lúdica nas ações de animais a partir da antropocentrização da experiência (associação do brincar animal com o brincar do ser humano) e nos desafiar a imaginar que insetos e plantas, por exemplo, também são susceptíveis a experiências lúdicas? Ao conceber a experiência lúdica como aquela que é significada pelo prazer ou alegria/felicidade, podemos associar o estado do prazer/alegria/felicidade à ideia de um "fluxo" (Csikszentmihalyi, 1990)6 ideal de sinergia intercorpórea-ambiental na qual uma esperada inter-ação positiva é antecipada. A partir dessa conceituação, poderíamos imaginar como experiências lúdicas, por exemplo, o momento no qual um gafanhoto encontra a corrente de vento que o levará à próxima fonte de alimento? Ou no qual uma borboleta monarca completa sua migração rumo ao seu refúgio de acasalamento nas florestas do México? Ou no qual uma árvore abre suas flores após o período de reclusão no inverno?

De maneira geral, pelo olhar apresentado nos últimos parágrafos, dissolve-se mais claramente a separação cartesiana do humano e do não-humano, criando cenários em que a ecomotricidade se distingue como perspectiva da relação corpo-ambiente: em oposição a uma "conexão" antropocêntrica à natureza (centralidade da ação do ser humano na natureza), a ecomotricidade é expressa como um movimento inerente de seres (humanos-e-não- -humanos) sendo-com-a-natureza. Essa pode ser a contribuição mais significativa do conceito de motricidade para uma presença ecológica (ecosomaestética-ambientalmente ética-ecopolítica) nas inter-ações ser-natureza: a intencionalidade e a transcendência não como características que distinguem os seres humanos de outros seres não-humanos (noção que contribui fortemente para uma visão antropocêntrica do ser-ao-mundo), mas como as qualidades exatas que vinculam todos os seres vivos em um movimento descentralizado e intercorpóreo de existência. Essa conceituação pode sustentar um design baseado na natureza que (ontologicamente/epistemologicamente/metodologicamente) se move de maneira diferente em direção à criação de significados em/para a educação crítica e ambientalmente justa.

\section{Percurso empírico}

Além das referências teóricas que aparecem em todas as seções do manuscrito como recurso para a fundamentação de contrastes argumentativos, as inferências apresentadas no artigo são também baseadas em dados coletados em pesquisa de campo a partir do desenvolvimento do plano de trabalho "A ecomotricidade no estado de Sergipe: construção de um corpo empírico", associado ao projeto "A ecomotricidade no estado de Sergipe".

As etapas do framework desse plano de trabalho envolveram: (1) entrevistas filmadas (posteriormente transformadas em texto a partir da transcrição lite-

\footnotetext{
${ }^{6}$ O conceito de "fluxo" apresentado sustenta-se na perspectiva do encontro entre um estado de alegria/prazer antecipado em determinado contexto e as condições ambientais para que tal estado de alegria/prazer seja satisfeito, resultando na experiência antecipada. Essa conceituação do termo é muito representativa para a compreensão das potencialidades lúdicas de corpos humanos e não-humanos. Csikszentmihalyi (1990) é citado como autor que desenvolve com maior profundidade o conceito de "fluxo"; no entanto, não se deve generalizar o conceito de "fluxo" apresentado neste artigo com todos os pontos levantados pelo autor em sua própria conceituação do termo. Sobre alguns questionamentos pertinentes sobre a teoria de "fluxo" de Csikszentmihalyi, inclusive em sua relação com estados lúdicos, sugere-se a leitura de Barnett (1976).
} 
ral); (2) diálogo entre colaboradores e pesquisadores enquanto ambos assistiam às entrevistas filmadas, sendo mudanças em respostas anteriores ou inclusão de novas informações anotadas em diários de campo; (3) autonarrativas livres dos colaboradores sobre eles mesmos (“Quem é...?”) e (4) sobre suas experiências na natureza, sendo a construção da narrativa aberta a diferentes expressões de linguagem (poesia; desenhos; fotografias; vídeos); (5) perfis de personalidade dos colaboradores elaborados por pessoas próximas (amigos e familiares), sendo as pessoas escolhidas pelos próprios colaboradores; (6) perfis de personalidade dos colaboradores a partir de representações em suas redes sociais (Facebook e Instagram), sendo a análise construída conjuntamente (colaborador e pesquisador) e as categorias de análise identificadas pelos próprios colaboradores; (7) etnografias em movimento, posteriormente descritas pelo pesquisador a partir de narrativas livres, também aberta a diferentes expressões de linguagem; e (8) glossário de expressões, no qual colaborador e pesquisador identificavam e registravam (durante todo o processo) particularidades linguísticas que refletem nuances das experiências na natureza.

A análise dos dados foi realizada, inicialmente, pela leitura crítica dos resultados obtidos a partir do desenvolvimento de cada etapa, destacando unidades de significado; ao final desse processo, foi realizada uma análise macro, compreendendo todo o conjunto de leituras específicas:

- Em relação às entrevistas (incluindo o diálogo sobre as respostas da entrevista com o colaborador), a leitura crítica compreendeu dois processos: (a) leitura de cada entrevista individual, destacando unidades de significado para a criação de um perfil do entrevistado a partir das respostas; (b) comparação transversal das respostas a cada pergunta (por exemplo: leitura das respostas à pergunta 1 das entrevistas $1 \mathrm{a} 18$ ), buscando similaridades e idiossincrasias entre os significados dados a cada pergunta. Ao final de cada leitura foi elaborado um parecer interpretativo em referência aos objetivos do projeto.

- A autodescrição em narrativa do colaborador, a descrição do colaborador por terceiros e a análise de perfis sociais do colaborador foram analisadas em conjunto e de forma comparativa. A análise compreendeu dois momentos: (a) análises individuais, construindo um perfil para cada indivíduo a partir de sua autonarrativa, da análise de seus perfis sociais e das descrições por terceiros; (b) análise comparativa, buscando similaridades e idiossincrasias entre os 18 perfis individuais. Ao final de cada análise, foi elaborado um parecer interpretativo em referência aos objetivos do projeto.

- As narrativas do colaborador sobre suas vivências na natureza, as etnografias em movimento e os glossários de expressões foram analisadas em conjunto e de forma comparativa. A análise compreendeu dois momentos: (a) análises individuais, construindo um perfil para cada experiência a partir das narrativas, das etnografias e dos glossários; (b) análise comparativa, buscando similaridades e idiossincrasias entre os 18 perfis individuais. Ao final de cada análise, foi elaborado um parecer interpretativo pelo pesquisador em referência aos objetivos do projeto.

Os pareceres interpretativos referentes à leitura crítica em cada etapa do processo formaram, em seu conjunto, a base para a macroanálise final. 


\section{Indo à coisa mesma}

Nesta seção, serão apresentados os resultados considerados mais significativos da análise empírica (considerando-se os objetivos do trabalho); tais resultados, em formato de "categorias", sustentam as inferências apresentadas no artigo, juntamente com os referenciais teóricos citados no manuscrito. Os resultados são devidamente contextualizados a partir da apresentação de unidades de significado extraídas do corpus; porém, serão apresentados apenas alguns exemplos representativos do conjunto de unidades destacadas na pesquisa, compreendendo os limites de caracteres desta publicação.

\subsection{Das personalidades}

Entre as diferentes marcas de personalidade dos colaboradores, três pontos se destacam na macroanálise: (a) indivíduos ativos, inquietos, que gostam de estar em movimento e, de certa forma, incomodam-se com a perspectiva de "ficar parado". Essa personalidade se manifesta em depoimentos como: "500 atividades ao mesmo tempo"; "220 volts; me dá até agonia se eu ficar parada"; "jovem de espírito, porque eu não consigo ficar muito tempo parado e eu relaxo quando estou fazendo atividades físicas"; "eu me sinto eu quando estou fazendo alguma atividade"; (b) ainda na perspectiva do "estar em movimento", transparece muito o gosto pelos esportes e pela atividade física, de maneira mais geral. Isso fica evidente em frases como: "gosta muito de esportes"; "de procurar aventura, praticante de quase todos os esportes"; "gosto muito, muito, muito de ler, viajar e claro de praticar esportes né"; (c) outra característica marcante é de uma atitude positiva em relação à vida, tanto em uma perspectiva mais individual (busca de boa vida para si - "vive a vida com a melhor forma possível que tem no dia"; "gosta de curtir a vida"; "de bem com a vida"; "apenas um jovem que quer ser livre") como em uma perspectiva mais coletiva (busca a boa vida também para outros - "um cara que acredita numa sociedade mais justa e igualitária"; "eu acredito que tudo que a gente faz pro outro é aquilo que a gente quer receber"; "sou uma pessoa altruísta"; "busco a felicidade das pessoas como um todo").

\subsection{Do gosto pelas experiências na natureza}

A criação do "gosto" pelas experiências na natureza (estética ambiental) está diretamente relacionada a três pontos mais representativos, pontos esses que, com frequência, se complementam: (a) a proximidade à natureza (“[...] e a facilidade que eu tinha de tá no mato, pela minha família ter terra, ter fazenda, então essa facilidade de estar e de me sentir segura no mato"; "morar perto da praia"; "pai tinha um empreendimento perto de uma pista de skate"; "Aracaju tem muito espaço pra essas atividades"); (b) vivências na natureza desde a infância ("desde criança eu sempre gostei da natureza"; "de muito pequeno"; "sempre gostei muito da água, desde pequena"; "desde criança eu sempre andei de bicicleta [...] elo entre a minha infância e a minha realidade"; "primeiro skate eu ganhei com 5 anos"); (c) influência de pessoas próximas que tinham vivências regulares na natureza ("influência das pessoas que me cercam desde muito nova; influência da minha mãe, dos hábitos da minha mãe, de gostar, de estar próximo à natureza [...]"; "pela influência assim, de pessoas próximas que praticavam”). 


\subsection{Da experiência em si}

A experiência em si é significada de maneiras bastante diferentes. Nota-se que a significação em uma mesma experiência pode mudar de acordo com a perspectiva que o colaborador constrói da experiência; isso pode ser percebido mais claramente quando se muda o foco das perguntas nas entrevistas (diferenças entre perguntas associadas a relações, a objetivos ou a sonhos, por exemplo), ou o método de coleta de dados (diferenças entre entrevistas e narrativas, por exemplo). Também é possível notar aproximações entre significações de colaboradores que vivenciam com regularidade uma mesma modalidade de experiência na natureza (skatistas ou surfistas, por exemplo); no entanto, as aproximações não permitem uma antecipação ou previsibilidade notória a partir de caracterizações generalistas (como comumente visto na reprodução de estereótipos direcionados a determinados grupos, novamente usando o exemplo de skatistas e surfistas), uma vez que há significações distintas entre colaboradores que vivenciam uma mesma modalidade, assim como aproximações de significação entre colaboradores que vivenciam diferentes modalidades.

O que a observação dos dados nos permite fazer é traçar um panorama das significações mais representativas das experiências em si, considerando o conjunto de narrativas; no entanto, apesar dessas significações, como descritas, formarem tipologias representativas, é importante destacar que as significações narradas estão inseridas em um contexto maior de vivência dos sujeitos, havendo constante integração e nuances entre essas tipologias:

a) A significação da experiência como um estilo de vida ("eu queria ter um estilo de vida daquele"); essa perspectiva transparece em depoi- mentos que associam diretamente as experiências na natureza com o modo que os colaboradores pensam e agem no mundo ("tudo relacionado à minha pessoa foi influenciado pelo skate; forma de me vestir, a forma de, de pensar; skate agregou muito em minha vida"; "a gente procura às vezes viajar pra um interior próximo para poder ter esse convívio com a natureza e praticando um esporte que a gente adotou, vamos dizer assim, como a vida"); ou no relato dessas vivências como "necessárias" para o modo de vida sustentando pelos colaboradores ("[relação é] de paixão, de necessidade; de sanidade, manter a sanidade mental"; "vai muito do coração, é...uma paixão que eu tenho, não consigo mais viver sem o skate, mesmo se tornando um hobby"; "Nossa... morar lá dentro!; na verdade eu queria fazer disso que hoje é uma válvula de escape a minha vida, eu queria poder, realmente, viver muito perto do mato");

b) A experiência como momento de (auto) reflexão ("momento de mergulhar dentro de si mesmo"; "uma relação mais reflexiva, eu acho que o SUP me permite isso, reflexão"; "a gente tem o privilégio de tá em contato com um silêncio muito grande e a sensação que a gente tem é que a gente consegue se ouvir"; "as reflexões que eu faço, as reflexões que eu não tenho a possibilidade de fazer no meu dia a dia que eu faço quando eu tô no SUP, eu levo pra lá essas considerações, essas conclusões, essas decisões saem daqui pra lá"); de renovação ("pra descarregar as energias ruins"; "é relaxamento, vida, contato com a natureza, um momento que você esquece dos problemas, de tudo, das coisas do dia a dia e vai apenas relaxar"; "Eu trago todo o estresse que a gente tem durante a semana e chego aqui às vezes até bem sóbria e quando eu saio, saio feliz da vida, saio bem aberta, uma coisa muito gostosa mesmo, eu acho que existe um interação a nível emocional nessa troca"; "momento que você 
se renova $[. .$.$] aqui o contato com a natureza dá uma$ paz de espírito"), sentimento que transparece muito na significação da experiência pelo sentimento que ela proporciona, associado principalmente a coisas boas, tais como paz, liberdade, plenitude, gratidão e contemplação espiritual/divina ("Plenitude! É você se sentir viva... é você se sentir... nossa... feliz!"; "momento de êxtase e depois que você termina uma sensação de paz"; "muita liberdade, muita alegria"; "é, recebe muito assim da natureza porque você sente mesmo aquela coisa, é coisa divina, maravilhoso"; "primeiro estágio é aquela adrenalina inicial; outro estágio é... é de calmaria; de gratidão [...]"; "um pouco de tensão com o equilíbrio, mas depois que passa esse momento é de paz, tranquilidade, relaxamento"); ou de contraposição ao cotidiano ("válvula de escape"; "conheço pessoas que têm aquela relação 'é bom, mas tá bom, já chega, agora já podemos voltar para a realidade"'; [Sobre o que leva do dia a dia para a experiência na natureza] "Nada (risos), geralmente eu sou outra pessoa no mar, a gente esquece dos problemas todos e lá é uma coisa e aqui é outra"; "[...] o nosso dia a dia nos estressa, nos deixa sempre com um faca nos dentes. Quando eu trago pro SUP é o contrário, é o antídoto pra tudo isso, é uma espécie de relaxamento").

Os relatos apresentados nessa perspectiva de reflexão/renovação (assim como na anterior, de estilo de vida) evidenciam um alto potencial de influência dessas experiências na formação de hábitos do indivíduo; essa significação aparece, inclusive, nas narrativas de histórias marcantes dos colaboradores em instâncias em que relatam experiências que poderiam ser potencialmente traumáticas ou extremamente negativas, porém quase sempre são apresentadas como aprendizados e superações que fortalecem ("teve uma hora que eu tive uma dificuldade, eu cai da prancha, não tava conseguindo subir na prancha por causa das ondas, aí eu disse, será que eu sou o próximo? E eu fiquei assim, me entreguei e a coisa ocorreu, foi uma sensação muito bancana"; "o rio tava jogando pro lado do mangue, no final acho que tinha o que, umas 8 ou 10 pessoas que começaram e só terminaram 3; mas foi muito massa, foi muito bom");

c) A experiência como esporte ("esporte radical"; "exige muita prática; ter frequência e o principal de todos, persistência"; "um esporte assim que aparentemente a gente não dá muito valor, porque a gente pensa que não...não exercita o corpo e na verdade ele exercita"; "esporte que me agrada"; "competição é comigo mesmo, diminuir meu tempo, aumentar a distância ou melhorar minha resistência"; "eu gosto de correr gosto de treinar, gosto de cronometrar"; "eu me relaciono mais assim para ir pra mais longe, mais ousado, mas é diferente a minha relação, porque eu, eu gosto de fazer uma competição interna comigo - até onde eu consigo aguentar? Quanto tempo eu consigo remar? Até onde começar a doer os pés, as mãos, os braços. E quando eu chego nesse ponto, pra mim é o ponto"; "o sonho de todo skatista ter um patrocínio bom véi, isso e viver do skate"; "porque o skate é um esporte de superação, se você não persistir você não consegue seu objetivo"); e meio para a saúde ("SUP é um esporte [...] é você praticar uma atividade para o seu bem estar físico, mental [...] para você tá uma mente boa você tem que está com o corpo sadio"; "remo e remo sistematicamente sempre com esse empenho de melhorar minha forma física e interagir com a natureza também"; "pra mim o SUP, ele entrou na minha vida de uma forma que é como se fosse o sétimo dia de academia, eu sou obrigada a ir, eu vou todos os dias para a academia e o SUP é o...o...a academia de domingo, eu sou obrigada a ir, eu tenho que ir"');

d) A experiência como momento lúdico ("num é por obrigação é por amor mesmo"; "qualquer 
praça que você for vai encontrar um skatista se divertindo"; "[relação é] a melhor de todas, é o que gosto de fazer"; "a gente volta ter aquele espírito de criança de brincar, de pedalar, de chegar aos nossos limites [...]"; "eu não anseio participar de competição, ando porque gosto mesmo da prática, me sinto bem andando de skate"), inclusive na exaltação estética da experiência ("Eu amo surfar!"; "[relação é] Rapaz, de amor"; "deu até vontade de chorar de tão bonito"); ou contexto de lazer ("se tornou um hobby"; "forma de lazer"; "[relação é] meia devagar, é... meia pra lazer"; "não é tipo uma obrigação; uma coisa mesmo como diversão, lazer, hobby”); essas significações ficam muito evidentes nos relatos de histórias que marcaram os colaboradores ("vi vários golfinhos nadando e fiquei emocionada"; "muitas viagens, muitas coisas boas, novas experiências") e na perspectiva de sonhos que os colaboradores têm em relação a suas experiências na natureza, muitas vezes sonhos de consumo tipicamente vendidos como o ideal máximo na perspectiva da experiência vivenciada ("conhecer a Califórnia né, que é o berço do skate"; "pegar um tubo [...] viajar para outros lugares, outras trip, outras ondas...tem o Peru também que eu tenho vontade"; "viajar pra Indonésia"; "conhecer o mundo andando de skate; desfrutar dos picos que, que tem aí ao redor do mundo [...]"; "assistir a Street League e ver o Luan de Oliveira ganhar"; "meu sonho era sair da Chapada até Itacaré [...] eu já pensei no São Francisco, uma saída de um ponto pra outro assim só"; "remar em outros locais, em outros estados, viajar com a minha esposa e com a galera, se for o caso também, pra gente praticar fora daqui de Aracaju”).

e) A experiência como interação com a natureza ("é você vivenciando a natureza no dia a dia"; "interação com a natureza realmente eu acho que é a parte mais importante do SUP"; "vejo que a maioria faz mais pra, pra apreciar, é, pra apreciar não, mas pra ter esse contato com a natureza"; "porque a ideia do nosso passeio não é velocidade, a ideia do nosso passeio é justamente o quê? Interagir com a natureza e aproveitar a paisagem dos percursos que a gente circula, que a gente passa"; "algumas pessoas não têm essa proximidade tão grande com a natureza, não esse espirito tão contemplativo, mas também amam tanto assim, porque muitas vezes tem um foco mesmo numa vida esportiva, e sensibilidade para a natureza é uma coisa muito pessoal, são níveis diferentes, são limiares diferentes de amor à natureza. Mas eu acredito, todo homem que se dispõe a remar num rio rodeado de mangue tem sempre um amor à natureza"; "por conta dessa interação com a natureza, com o meio ambiente, a oportunidade de ajudar na preservação do meio ambiente"; "Eu procuro sempre é...prestar atenção muito na natureza, a natureza conversa com a gente e o que eu mais faço quando eu vou remar e que eu tô em contato com a natureza é ouvi-la, é ouvir o barulho dos caranguejos, que eu acho maravilhoso, eu adoro, eu tiro muito foto no mangue, ouvir os pássaros... é... procurar enxergar nos rios, peixes, eu já vi boto, esse bichos assim, tartaruga, essas coisas. Isso que eu acho importante e eu procuro fazer isso").

\section{Tempo e imersão}

Considerando a apreensão de horizontes da natureza a partir da ecomotricidade, ou seja, a partir de experiências lúdicas na natureza, especialmente na incorporação de preceitos ecosomaestéticos-ambientalmente éticos-ecopolíticos no habitus de movimento dos indivíduos (objetivo central deste artigo), dois elementos particulares se destacam na macroanálise da com-vivência com os colaboradores da pesquisa: tempo e imersão. Durante os primeiros encontros entre pesquisadores e colabo- 
radores, especialmente durante a entrevista inicial, as representações de natureza apresentadas pelos colaboradores claramente reproduziam jargões comumente associados a representações socialmente construídas de natureza e das atividades na natureza ${ }^{7}$. No entanto, o processo etnográfico/ecofenomenológico de com-vivência associado à própria pesquisa possibilitou aos colaboradores a constante reflexão sobre suas próprias experiências: como as respostas que deram durante as entrevistas iniciais contrastavam com suas próximas experiências na natureza, com suas expressões em narrativas livres (frequentemente expressas a partir de poesias, desenhos, fotos e filmes curtos), com as experiências compartilhadas nas etnografias em movimento; como a maneira em que descreveram a si próprios na entrevista contrastava com sua narrativa autodescritiva mais detalhada elaborada posteriormente, com as descrições de seus amigos e familiares, com as personalidades construídas e expressas a partir de seus perfis sociais públicos, sobretudo, quanto e de que maneiras essas representações pessoais são influenciadas pelo seu engajamento em experiências na natureza; por fim, como expressões particulares de suas inter-ações na natureza (glossário) representam aspectos estéticos-éticos-políticos dessas experiências.

De maneira geral, a contínua suspensão fenomenológica das "memórias" da experiência possibilitada pela própria metodologia de pesquisa provocou constantes questionamentos sobre diferentes maneiras em que os colaboradores estão sendo-no-mundo, assim como contrastes dessas memórias com suas aspirações estéticas-éticas-políticas em contextos lúdicos. Essa dinâmica dialógica do indivíduo com suas próprias significações sobre si e sobre suas experiências na natureza, construídas pelo tempo e pela imersão, manifestaram-se em momentos posteriores da pesquisa menos como intencionalidades à saúde, qualidade de vida ou performance, e mais pela intencionalidade do prazer e da felicidade significados e expressos como amor, paz, alegria, plenitude, espiritualidade e sinergia com a natureza. Dessa forma, a desconstrução etnográfica-(eco)fenomenológica do processo metodológico revelou limitações e excessos da linguagem, na medida em que a linguagem condiciona (seletivamente) as experiências ambientais de acordo com padrões estreitos de representações da relação ser-natureza. A reprodução (linguística) desses padrões restringe as possibilidades de diversificação (corporal) das vivências corpo-natureza; ao contrário, contextos kairos e chora, assim como a regularidade de imersão (com-vivência), aparecem como instâncias de questionamento nas quais padrões linguísticos-corporais dão lugar a uma relação caracterizada pelo encontro das disponibilidades/possibilidades estruturais do ambiente e a capacidade estrutural do agente em perceber o que é acessível às suas ações (retomando o conceito de affordance de J. J. Gibson, 1979).

Eludir idealismos da linguagem é crucial para a superação de maneiras de pensar, agir, ser/existir já incorporadas (in-corpo-radas) ou naturalizadas, no sentido em que não são mais questionados pelo indivíduo. A “dissonância corporal” (Payne, 2014) provocada pela qualidade ecofenomenológica do framework metodológico da pesquisa possibilitou que os colaboradores continuamente desconstruíssem e reconstruíssem suas significações sobre suas próprias experiências na natureza, desafiando os idealismos da linguagem naturalizados como

\footnotetext{
${ }^{7}$ Sobre expressões mais comumente utilizadas (jargões) para descrever motivações e sentimentos associados a experiências na natureza, ver, por exemplo, Tahara et al. (2006) e Bahia \& Sampaio (2007).
} 
representações padronizadas do movimento em experiências na natureza. No entanto, esse processo só foi possível pela relação de tempo e imersão que os colaboradores têm com experiências na natureza (média de uma vez por semana nos últimos dois anos, ou mais), possibilitando reflexões comparativas a partir das dissonâncias corporais (linguagem-representações/expressões-práticas-sentimentos) entre suas memórias de experiências na natureza e a própria vivência da pesquisa.

Ainda no contexto do exemplo empírico apresentado, destaca-se a relação direta e generosa entre colaborador e pesquisador, incluindo nas dimensões estéticas e afetivas, desconstruindo o idealismo de uma relação neutra nesse contexto. Contrariando o princípio de realidades generalizáveis e causais, singularidades são reconhecidas como significantes e genuínas. Nessa perspectiva, abrem-se caminhos para metodologias que reconhecem a necessidade de valorização dos elementos afetivos e estéticos da/na pesquisa (Payne et al., 2018). Totalmente exposto, o pesquisador reconhece seu papel ético e político como um formador de opinião, assumindo as responsabilidades do não-anonimato, apresentando fielmente e se comprometendo com os resultados da pesquisa, estando aberto ao diálogo, aceitando criticismo e criticando seus pares quando necessário (Rodrigues, 2018).

\section{Síntese crítica}

No esforço de sintetizar os argumentos apresentados em relação às possibilidades de incorporação de preceitos ecosomaestéticos-ambientalmente éticos-ecopolíticos no habitus de movimento de indivíduos a partir de experiências lúdicas na natureza, esta última seção apresenta alguns princípios genéricos da ecomotricidade, sendo possível a transferibilidade (não generalização) para outros contextos práticos e diferentes enquadramentos de pesquisa, considerando-se as devidas particularidades geo-epistemológicas.

a) Conceituação de um mundo de movimento no qual o significado é essencialmente criado na/ pela motricidade. Ecofenomenologicamente, a motricidade é conceituada como o movimento inerente, descentralizado e intercorpóreo de existência que liga todos os seres vivos. A partir dessa concepção, as "dissonâncias corporais" que florescem nas experiências de ecomotricidade têm inclinações e implicações ecológicas (estéticas-éticas-políticas) profundas. As discussões sobre motricidade precisam de mais terreno na academia; as considerações sobre a ecomotricidade precisam de mais terreno nos espaços em que a motricidade já é legitimada como campo da prática e de pesquisa.

b) Estudos sobre a história das representações sociais e sobre o conhecimento construído/produzido. Os padrões de movimento (na natureza) são constituídos coletivamente, condicionando formas de pensar e formas de fazer. Aprender sobre esses padrões é essencial para entender as possibilidades e limitações de proposições e práticas relacionadas à apreensão das representações da natureza. Uma rede de estudos sobre as representações sociais das experiências na natureza em diferentes contextos geo-culturais/históricos contribuirá de forma significativa para (re)pensar possibilidades ecológicas das motricidades (humanas-e-não-humanas).

c) "Ir à coisa mesma", aprendendo com aqueles que experimentam o fenômeno. Um conceito fundamental da fenomenologia transcendental e intersubjetiva, reformulado pela ecofenomenologia inerente e intercorpórea, especialmente por meio de etnografias em movimento como ecologias dos seres e das coisas. A incorporação de uma ecofenomenologia do movimento "vivido" em vários 
ambientes e seus horizontes em uma noção e prática emergentes de interações ecológicas em lócus variados, como educação, turismo, promoção da saúde e espaços abertos, urbanos e naturais, é vista como potencialmente significativa para responder a alguns dos limites ontológicos das epistemologias que presumem a mudança racional desincorporada, não intercorpórea, muitas vezes invocadas de forma acrítica na promoção de comportamentos supostamente "pró-ambientais". Estudos que investigam aspectos fundamentais de como a ecomotricidade é experimentada em diferentes contextos geo-culturais/históricos (particularidades locais/regionais; tendências regionais/globais) podem oferecer contrastes importantes para fundamentar designs conceituais, empíricos e metodológicos.

d) A essencialidade do tempo (lento, disponível, lúdico, kairos) e da imersão (intercorpórea, em-ação, chora), que são condições ainda raramente satisfeitas em proposições ecológicas. As dissonâncias (inter)corpóreas potenciais resultan-

\section{Referências}

Bahia, M. C.; Sampaio, T. M. V. Lazer e meio ambiente: em busca das atitudes vivenciadas nos esportes de aventura. Revista Brasileira de Ciências do Esporte, 28(3), 173-189, 2007. Disponível em: http://revista.cbce.org.br/index.php/ RBCE/article/view/30/37

Barnett, L. Play and intrinsic rewards: a reply to Csikszentmihalyi. Journal of Humanistic Psychology, 16(3), 83-87, 1976. doi: 10.1177/002216787601600312.

Bourdieu, P. O poder simbólico. Rio de Janeiro: Bertrand Brasil, 1989.

Brown, C. S.; Toadvine, T. Eco-Phenomenology: back to the earth itself. Albany: State University of New York Press, 2003.

Carvalho, I. C. M. Ambientalização, cultura e educação: diálogos, traduções e inteligibilidades possíveis desde um tes de experiências imediatas e esporádicas em/ $\mathrm{com} /$ sobre a natureza podem levar a estimulantes e até mesmo generativas afeições/efeitos sobre as relações ser-natureza. No entanto, transformações ecológicas significativas e ambientalmente éticas e ecopolíticas no habitus de movimento individual e coletivo exigem um tipo específico de relação com o tempo e com o espaço. Designs metodológicos específicos precisam ser desenvolvidos pensando sobre essas particularidades.

As possibilidades apresentadas são decorrentes de pesquisas realizadas em contextos geo-epistemológicos particulares. Reconhecendo-se, no entanto, as possíveis limitações em contraste com outras configurações geo-culturais/históricas, a síntese apresentada acima sugere uma contribuição inicial para as discussões sobre as possibilidades de incorporação de preceitos ecosomaestéticos-ambientalmente éticos-ecopolíticos no habitus de movimento de indivíduos a partir de experiências lúdicas na natureza. estudo antropológico da educação ambiental. Revista Eletrônica do Mestrado em Educação Ambiental, v. especial, 28-39, 2010. Disponível em: https://periodicos.furg.br/ remea/article/view/3393/2052

Csikszentmihalyi, M. Flow: The Psychology of Optimal Experience. New York, NY: Harper and Row, 1990.

Fiori, E. M. Conscientização e educação. Educação e Realidade, 11(1), 3-10, 1986. Disponível em: https://seer.ufrgs. br/educacaoerealidade/issue/viewIssue/3068/334

Gallagher, S. Intercorporeity: Enaction, simulation and the science of social cognition. In: Reynolds, J.; Sebold, R. (Eds.). Phenomenology and Science. London: Palgrave-Macmillan, 2016. p. 161-179.

Gibson, J. J. The ecological approach to visual perception. Boston: Houghton Mifflin, 1979. 
Husserl, E. Elementos para uma elucidação fenomenológica do conhecimento. In: Husserl, E. Investigações lógicas; sexta investigação. São Paulo: Nova Cultural, 1988. p. 1340. (Coleção Os Pensadores)

Ingold, T. Being alive: essays on movement, knowledge and description. Abingdon: Routledge, 2011.

Ingold, T. The perception of the environment: Essays on livelihood, dwelling and skill. Abingdon: Routledge, 2000.

Merleau-Ponty, M. Fenomenologia da percepção. São Paulo: Martins Fontes, 2. ed., 1996.

Payne, P. Embodiment and environmental education. Environmental Education Research, 3(2), 5-34, 1997.

Payne, P. (Un)timely ecophenomenological framings of environmental education research. In: Stevenson, R. B.; Brody, M.; Dillon, J.; Wals, A. E. J. (Eds.). International Handbook of Research on Environmental Education. Routledge, NY and London, 2013. p. 424-437.

Payne, P. Vagabonding slowly: Ecopedagogy, metaphors, figurations, and nomadic ethics. Canadian Journal of Environmental Education, 19, 47-69, 2014.

Payne, P. Critical curriculum theory and slow ecopedagogical activism. Australian Journal of Environmental Education, 32(2), 1-29, 2015.

Payne, P. et al. Affectivity in environmental education research. Pesquisa em Educação Ambiental, 13(Especial), 93114, 2018. Disponível em: http://www.periodicos.rc.biblioteca.unesp.br/index.php/pesquisa/article/view/12463/8530
Rodrigues, C. O jogo, o esporte e o lazer na constituição do ideário ambiental. Licere, 18(1), 29-55, 2015. Disponível em: https://periodicos.ufmg.br/index.php/licere/article/view/1074

Rodrigues, C. Movement Scapes as ecomotricity in ecopedagogy. The Journal of Environmental Education, 49(2), 88-102, 2018. doi: 10.1080/00958964.2017.1417222

Rodrigues, C.; Gonçalves Junior, L. Ecomotricidade: sinergia entre educação ambiental, motricidade humana e pedagogia dialógica. Motriz, 15(4), 987-995, 2009. Disponível em: http://www.periodicos.rc.biblioteca.unesp.br/ index.php/motriz/article/view/3252/2759

Rodrigues, C. et al. Teorias do lazer: contribuições da fenomenologia. In: Pimentel, G. G. A. (Org.). Teorias do Lazer. Maringá: Eduem, 2010. p. 73-102.

Rodrigues, C.; Stevaux, R. P. Do Chronos ao Kairos: Os tempos da educação para o lazer. Lazer e Sociedade, 1, 28-42, 2010.

Sérgio, M. Um corte epistemológico: da educação física à motricidade humana. Bobadela: Instituto Piaget, 2. ed., 2003.

Sheets-Johnstone, M. The corporeal turn: an interdisciplinary reader. Exeter: Imprint Academic, 2009.

Tahara, A. K. et al. Meio ambiente e atividades de aventura: significados de participação. Motriz, 12(1), 59-64, 2006. Disponível em: http://www.periodicos.rc.biblioteca.unesp. br/index.php/motriz/article/view/61/42

Walter, E. V. Placeways: a theory of the human environment. Chapel Hill: The University of North Carolina Press, 1988. 